\title{
Treatment of Mycobacterium abscessus Complex
}

\author{
Luke Strnad, MD ${ }^{1}$ Kevin L. Winthrop, MD, $\mathrm{MPH}^{1,2}$ \\ ${ }^{1}$ Division of Infectious Diseases, Department of Medicine, Oregon \\ Health and Sciences University, Portland, Oregon \\ 2 Department of Epidemiology and Epidemiology and Medicine, \\ Oregon Health and Sciences University and Portland State University \\ School of Public Health, Portland, Oregon
}

Semin Respir Crit Care Med 2018;39:362-376.

\author{
Address for correspondence Luke Strnad, MD, 3188 SW Sam Jackson \\ Park Road, Mail Code: L457, Portland, OR 97239 \\ (e-mail: strnad@ohsu.edu).
}

\begin{abstract}
Keywords

- Mycobacterium abscessus treatment

- Mycobacterium abscessus

- Mycobacterium massiliense

- Mycobacterium bolletii

- bronchiectasis

- cystic fibrosis

Of the nontuberculous mycobacteria (NTMs) causing lung disease, members of the Mycobacterium abscessus complex (MABc) present a formidable obstacle to successful management. This challenge starts from a poorly understood pathogenesis, continues with complicated subspecies variation in treatment response, and extends to the multidrug-resistant nature of these organisms. The disease often necessitates the use of intravenous therapy, toxic drug combinations, and, in some cases, lung resection. Like many NTMs, MABc treatment requires prolonged therapy with multiple medications, and pulmonary disease in some subspecies can be impossible to eradicate or cure. This disease also represents a frequent and unique problem in certain populations, including cystic fibrosis and lung transplant recipients, and providers who manage such patients should be familiar with how $M A B c$ disease influences management. Because of the rising prevalence of the $M A B c$, especially in patients with complicated underlying pulmonary disease, it is increasingly necessary for infectious diseases and pulmonary medicine clinicians to understand the unique aspects of $M A B C$ management and understand when to obtain expert consultation in the care of these patients.
\end{abstract}

Mycobacterium abscessus complex (MABc) is the second most common nontuberculous mycobacteria (NTM) grouping causing human disease after Mycobacterium avium complex (MAC). ${ }^{1,2}$ MABc causes a wide spectrum of human disease, most commonly pulmonary disease, although it can cause soft tissue disease, bone disease, and disseminated disease in immunocompromised hosts. ${ }^{1,3}$ The spectrum of infection severity is heterogeneous, ranging from asymptomatic colonization to progressive and mortal disease., ${ }^{4,5}$ Unfortunately, MABc is a highly drug-resistant organism and few oral antibiotics show in vitro activity, making long-term treatment of this infection extremely complicated. ${ }^{1,4,5}$ In this article, we will review the treatment of MABc pulmonary disease as well as its epidemiology, disease manifestations, and aspects of its diagnosis that are germane to disease management.

\section{Microbiology and Epidemiology}

\section{Mycobacterium abscessus Complex Taxonomy}

MABc is one of a group of NTM "rapid growers," which includes Mycobacterium fortuitum complex, Mycobacterium chelonae, and $\mathrm{MABc}$, all having the characteristic of growing within 7 days on solid media subculture (faster in liquid media) as well as the ability to grow in standard blood culture. ${ }^{1,5}$ It was only in 1992 that MABc organisms could be identified as distinct from $M$. chelonae and thus these organisms are undifferentiated in literature published before that time. ${ }^{1,5,6}$ As recently as 2006, M. abscessus was reclassified to represent a complex containing three subspecies: $M$. abscessus, Mycobacterium massiliense, and Mycobacterium bolletii. $^{1,5}$ Over the subsequent 7 years, the taxonomic and nomenclature classifications for these organisms have

Copyright (c) 2018 by Thieme Medical Publishers, Inc., 333 Seventh Avenue, New York, NY 10001, USA. Tel: +1(212) 584-4662.
DOI https://doi.org/ 10.1055/s-0038-1651494. ISSN 1069-3424.
Evolving Concepts; Guest Editors: Patrick A. Flume, MD, and Kevin L. Winthrop, $\mathrm{MD}, \mathrm{MPH}$ 


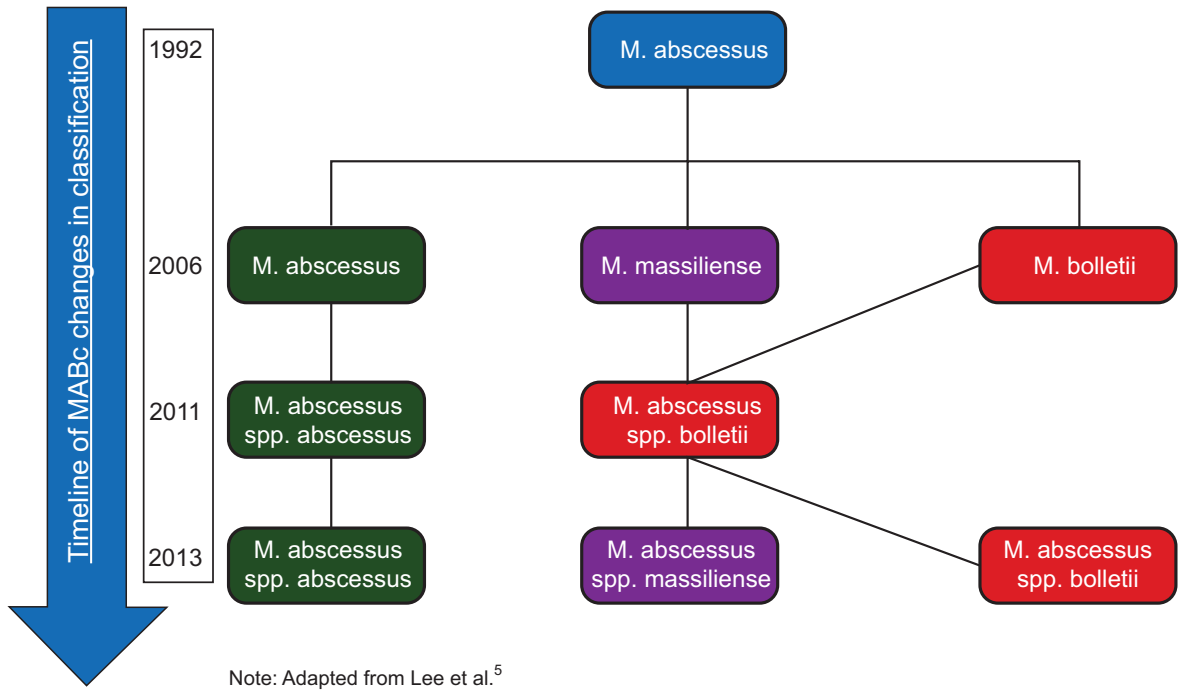

Fig. 1 Changes over time to subspecies organization of MABc. (Adapted from Lee et al..$^{5}$ )

undergone additional changes resulting in the current understanding of MABc (-Fig. 1). ${ }^{5}$ It can be difficult to analyze literature regarding " $M$. abscessus" treatment as many studies do not separately analyze these subspecies, which have differential drug susceptibilities and accordingly differential treatment success. Additionally, since early studies did not differentiate between $M$. abscessus and M. chelonae, it is difficult to judge the results of these studies, as $M$. chelonae is often a colonizer or contaminant. ${ }^{1}$

\section{Organism Microbiology}

Several microbiologic features of MABc are important to highlight because of their implications for disease management. First, like many NTM species, these organisms are ubiquitous in soil and water environments. ${ }^{1,7,8}$ As a result, patients with an underlying predilection to initial infection (e.g., bronchiectasis, other structural lung disease) have a high risk of reinfection after adequate treatment, as well as a risk of infection with different strains of the same organism. ${ }^{9,10}$ Second, the organisms have a propensity for biofilm formation. This protects them not only from the immune response but also from antibiotics, both of which make true eradication very difficult. ${ }^{8,11}$ Third, the presence or absence of a functional erm gene (RNA methylase gene), discussed in more detail in next sections, has important implications for drug resistance to macrolide antibiotics. Since this drug class constitutes the most effective oral antibiotic for susceptible NTM organisms, this biology is crucial to treatment choice and response. $^{12-14}$ Fourth and least well understood, there appears to be other genotypic variations within the MABc subspecies that influence disease manifestations and treatment response. ${ }^{15-17}$

\section{Disease Epidemiology}

Along with most other NTM infections, the incidence and prevalence of MABc pulmonary infections appears to be increasing, although it is unclear what role increased awareness and improved diagnostics is playing in this process. ${ }^{18-20}$ Of the complex subspecies (subsp), subsp abscessus is generally the most common, although there are notable geographic variations in this finding with subsp massiliense even more prevalent in some regions (-Table 1). ${ }^{4}$ Since not all

Table 1 MABC propotions of M. abscessus, M. massiliense, M. bolletii

\begin{tabular}{|c|c|c|c|c|c|}
\hline Study & Location & Total number & M. abscessus (\%) & M. massiliense (\%) & M. bolletii (\%) \\
\hline Zelazny, $2009^{143}$ & United States & 40 & 67.5 & 27.5 & 5 \\
\hline van Ingen, $2009^{22}$ & Netherlands & 39 & 64 & 21 & 15 \\
\hline Roux, $2009^{24}$ & France & 50 & 60 & 22 & 18 \\
\hline Harada $2012^{144}$ & Japan & 102 & 71 & 26 & 3 \\
\hline Yoshida $2013^{46}$ & Japan & 143 & 63 & 35 & 2 \\
\hline Nakanaga, $2014^{35}$ & Japan & 115 & 60 & 37 & 3 \\
\hline Huang, $2013^{105}$ & Taiwan & 79 & 43 & 56 & 1 \\
\hline Kim, $2008^{145}$ & South Korea & 126 & 53 & 45 & 2 \\
\hline Koh, $2011^{23}$ & South Korea & 158 & 44 & 55 & 1 \\
\hline Lee, $2014^{146}$ & South Korea & 404 & 50 & 49 & 1 \\
\hline
\end{tabular}

Note: Adapted from Koh et al. ${ }^{4}$ 
laboratories can perform subspecies identification and the process of getting results from a reference laboratory can take many weeks, knowledge of local epidemiology can be helpful in crafting empiric antibiotic regimens if they are needed while waiting further subspecies identification. That said, since subsp abscessus is the most drug-resistant of the group and since in no region is the prevalence low enough to ignore, empiric treatment of $\mathrm{MABc}$ should consider subsp abscessus.

Another nuance in the evaluation of MABc literature and clinical management of the disease is the fact that in the respiratory tract, culture positivity (infection) does not inherently mean disease. ${ }^{1,21}$ In the lungs, all subspecies can behave in a nonpathogenic way, essentially "colonizing" the airway with minimal clinical impact. 1,21,22 Other times, the organisms can cause airway inflammation without causing parenchymal lung disease. In both situations, infection can become progressive within the airway and surrounding lung parenchyma, ultimately causing disease. Sputum culture positivity does not definitively indicate which situation is true in a patient at any given moment. ${ }^{1}$ This has implications for treatment but also for interpreting literature in which it is not always clear whether patients included in studies have "colonization" versus "disease," which can change reporting on manifestations and treatment response; therefore, this word of caution must be kept in mind when interpreting published literature.

\section{Clinical Features of Mycobacterium abscessus Complex Pulmonary Disease}

An overwhelming majority of the cases of MABc pulmonary infection and disease occur in hosts with underlying lung disease. ${ }^{9,15,22,23}$ This can be airway disease such as bronchiectasis, which allows accumulation of and prevents clearance of environmental colonizing microorganisms, or parenchymal disease such as emphysema or pulmonary fibrosis, which by causing destruction and impaired circulation at the tissue level inhibits immune surveillance against and clearance of foreign microbes. This susceptibility to infection is particularly pronounced in patients with cystic fibrosis (CF), who have bronchiectasis but also airway ciliary deficiencies creating a unique clinical phenotype covered in detail later in this review. ${ }^{24-26}$ Because all the above physiology allows other organisms to gain easier access to the respiratory tree as well, individuals with MABc pulmonary infection are usually colonized with and often infected with other pathogens. ${ }^{9,27}$ Treatment sometimes needs to take these organisms into account or clinicians need to consider a superinfection with these other organisms as one of the possible reasons for worsening in a MABc patient on therapy. There is a poorly understood interplay of the lung microbiome here, and in some patients, treatment of MABc allows other pathogens to flare (and vice versa) as organisms compete for resources within the airway. ${ }^{28,29}$

$\mathrm{MABc}$ pulmonary infection typically presents in an indolent fashion with waxing and waning symptoms, and many patients do not have significant progression for months or years after infection., $1,30,31$ In light of this, treatment initiation is not always indicated even if disease criteria described below is met, and when it is indicated, this is rarely urgent. ${ }^{1}$ Like MAC, the presentation is typically scattered nodular infiltrates in or around areas of structural lung disease. ${ }^{1,9,15}$ Also like MAC, less commonly the disease can be cavity-forming or superinfect structural lung cavities, and it is not clear whether or not cavity formation is more common with $\mathrm{MABc}$ or MAC. ${ }^{15,32}$ Because of the higher mycobacterial burden and less optimal blood supply within these areas of cavitary physiology, the presence of cavities has implication for treatment decisions. ${ }^{1}$ Coinfection with MAC is not uncommon and MABc can be seen in up to $50 \%$ of pulmonary MAC cases in some series. ${ }^{9,30}$ An estimated 15 to $30 \%$ of MABc cases have MAC isolated from their sputum as well. ${ }^{33}$ Coinfection presents a clinical conundrum as it can be difficult to ascertain which organism is playing a pathogenic role (or if both are) and should be targeted for therapy. ${ }^{1,33}$

\section{Diagnosis of Infection versus Disease}

The identification of MABc is still largely culture-based, although new technologies are revolutionizing laboratorybased diagnostics in this area. ${ }^{34,35}$ However, microbe identification (infection) does not equal disease, especially in pulmonary specimens, so pulmonary disease diagnosis is worth reviewing in any discussion of treatment. American Thoracic Society guidelines for pulmonary NTM disease are listed below: ${ }^{1}$

- Symptoms attributable to an infection with the organism.

- At least two positive sputum cultures or one positive bronchoalveolar lavage or lung biopsy culture with the organism.

- Radiographic changes compatible with infection with the organism.

In addition to the potential of nonpathogenic colonization, organisms in MABc can occasionally be contaminants of the laboratory process because of their prevalence in nonsterile environments; thus, as with most infectious diseases, isolation from a site without clinical evidence of pathology should be viewed with suspicion. ${ }^{1,7}$

\section{Drug Resistance and Susceptibility Testing}

As mentioned previously, organisms in the MABc are highly drug resistant and understanding their resistance properties and laboratory ways to identify them is a crucial part of treatment.

\section{Slow Growth}

Compared with most other pathogens, even rapid-growing mycobacteria are slow growing. This property creates treatment difficulties for multiple reasons. Since many antibiotics work at least partly on dividing pathogens, slow cell replication means slower rates of antibiotic activity. Of the antibiotics typically used to treat $\mathrm{MABc}$, this property limits the efficacy of $\beta$-lactams (BLs) and means most of the antibiotic classes used 
rely on targeting ribosomal protein synthesis, which is not dependent on bacterial division (macrolides, tetracyclines, aminoglycosides, fluoroquinolones, oxazolidinones). ${ }^{36}$ The slow growth of the organisms also makes culture-based susceptibility testing time-consuming and difficult.

\section{Waxy Cell Wall Barrier}

The cell wall of MABc has a high lipid content, creating a waxy barrier that is difficult for antibiotics to penetrate. ${ }^{37}$ This fact alone is potentially sufficient to confer resistance to many BLs and likely impairs susceptibility to aminoglycosides. $^{38}$ Even when not completely impermeable, by lowering the antibiotic concentration within the bacteria, the cell wall plays a role in allowing other resistance mechanisms to be protective when they would otherwise be overwhelmed by high enough antibiotic concentrations. ${ }^{39}$

\section{Biofilm Formation}

Biofilm formation is protective for many microbial organisms by creating a surrounding environment that is poorly penetrated by the immune system and antibiotics. Biofilms also create an environment within which bacteria can survive despite less metabolic activity, rendering them more resistant not only to antibiotics that target cell division but also to protein synthesis and adenosine triphosphate (ATP) synthesis processes. ${ }^{11,40} \mathrm{MABc}$ has been described to form these biofilms in airways, alveoli, and pulmonary cavities, which likely explains part of its resistance to treatment and the difficulty with infection eradication. ${ }^{11,41,42}$

\section{Drug-Neutralizing Enzymes and Export Systems}

There are many neutralizing enzymes and drug export systems that enhance the ability of MABc to survive antibiotic exposure (-Table 2), including an adenosine diphosphate (ADP)-ribosyltransferase and mono-oxygenase that may confer the complexes known rifampin resistance. ${ }^{36,43}$ The most importance of these resistance mechanisms is an inducible erm gene which is present in some members of the MABc and confers macrolide resistance that is expressed upon macrolide exposure. ${ }^{44}$ This mechanism is notable both for the important role macrolides play in management of NTM infections and because of the difficulty in identifying its presence. Since it is an inducible enzyme, the mechanism will not be picked up on in vitro antibiotic susceptibility testing unless this testing is done after incubating the organism in the presence of macrolides for 14 days. ${ }^{1,44}$ As a result, the Clinical and Laboratory Standards Institute (CLSI) recommends that macrolide testing for this complex include prolonged incubation testing for inducible macrolide resistance. ${ }^{1,45}$ Additionally, the erm gene can be present and inactive, so molecular tests that only probe for the presence of the gene do not conclusively prove macrolide resistance. ${ }^{14,36}$ Since many laboratories are not capable of performing prolonged drug incubation and do not have the molecular diagnostics to either identify the erm gene or identify if it is active, accurate macrolide susceptibility testing may require sending the isolate to a mycobacterial-specific reference laboratory. Labs that report macrolide susceptibility without performing appropriate testing may provide results that mislead the untrained provider leading to suboptimal treatment regimens. An active erm gene is present in most MABc subsp abscessus isolates, in some subsp bolletii, and in a small proportion of subsp massiliense. ${ }^{12,13,46}$

\section{Genetic Polymorphisms}

Because of specific genetic polymorphisms within the MABc, these organisms are less susceptible to antibiotics than most other mycobacteria (higher minimum inhibitory concentrations, MICs). Classic in this regard are a couple base-pair substitutions in the embB ethambutol resistance determining region which confer high-level (MICs $>64 \mathrm{mg} / \mathrm{L}$ ) ethambutol resistance to all members of the MABc. ${ }^{47}$ Although the $\mathrm{MABC}$ is not intrinsically resistant to fluoroquinolones, only a

Table 2 Possible mechanisms of resistance of $M A B C$

\begin{tabular}{|c|c|c|c|}
\hline Antibiotic & Locus and genes & Proteins involved & Resistance mechanism \\
\hline Hydrophilic antibiotics & - & - & $\begin{array}{l}\text { Selective permeability of } \\
\text { cell envelope }\end{array}$ \\
\hline \multirow[t]{6}{*}{ Aminoglycosides } & MAB_4395 & Aminoglycoside 2-N-acetyltransferase & \multirow[t]{6}{*}{ Antibiotic-modifying enzymes } \\
\hline & MAB_0327 & \multirow[t]{5}{*}{ Aminoglycoside phosphotransferases } & \\
\hline & MAB_0951 & & \\
\hline & MAB_3637c & & \\
\hline & MAB_4910c & & \\
\hline & MAB_4395 & & \\
\hline Rifampicin & MAB_0951 & Rifampicin ADP-ribosyltransferase & - \\
\hline Beta-lactams & MAB_2875 & Beta-lactamase & Antibiotic-degrading enzymes \\
\hline \multirow[t]{2}{*}{ Macolides } & erm(41) gene & \multirow[t]{2}{*}{ 23S RNA methyltransferase } & \multirow[t]{2}{*}{ Target-modifying enzymes } \\
\hline & MAB_2297 & & \\
\hline Several antibiotics & scattered in genome & ABC transporters. Mmpl. family & Efflux pumps \\
\hline
\end{tabular}

Note: Adapted from Nessar et al. ${ }^{36}$ 
Table 3 CLSI MIC Breakpoints for MABC

\begin{tabular}{|l|l|l|l|}
\hline \multirow{2}{*}{ Antimicrobial } & \multicolumn{3}{|c|}{ MIC for broth dilution $(\mu \mathrm{g} / \mathrm{mL})$} \\
\cline { 2 - 4 } & Susceptible & Intermediate & Resistant \\
\hline Amikacin & $\leq 16$ & 32 & $\geq 64$ \\
\hline Cefoxitin & $\leq 16$ & $32-64$ & $\geq 128$ \\
\hline Clarithromycin & $\leq 2$ & 4 & $\geq 8$ \\
\hline Ciprofloxacin & $\leq 1$ & 2 & $\geq 4$ \\
\hline Doxycycline & $\leq 1$ & $2-8$ & $\geq 16$ \\
\hline Imipenem & $\leq 4$ & 8 & $\geq 16$ \\
\hline Linezolid & $\leq 8$ & 16 & $\geq 32$ \\
\hline Moxifloxacin & $\leq 1$ & 2 & $\geq 4$ \\
\hline $\begin{array}{l}\text { Trimethoprim- } \\
\text { sulphamethoxazole }\end{array}$ & $\leq 2 / 38$ & $\mathrm{n} / \mathrm{a}$ & $\geq 4 / 76$ \\
\hline Tobramycin & $\leq 4$ & 8 & $\geq 16$ \\
\hline
\end{tabular}

Note: Adapted from National Committee for Clinical Laboratory Standards (CLSI). Susceptibility testing of mycobacteria, nocardiae, and other aerobic actinomycetes. Approved Standard. Wayne, PA: NCCLS; 2011. Document No. M24-A2. ${ }^{45}$

couple point mutations are needed in DNA gyrase subunits A and $\mathrm{B}$ to confer fluoroquinolone resistance (MICs $>8 \mathrm{mg} /$ L). ${ }^{48}$ This combined with the frequent use of fluoroquinolones for a variety of medical conditions, and almost ubiquitous use in agriculture, means that a sizeable proportion of $\mathrm{MABC}$ organisms are quinolone-resistant even if the patient has not received prior quinolone therapy for their mycobacterial disease. ${ }^{4-51}$ Aminoglycoside resistance can also develop more easily than with other bacteria as MABc only possesses a single copy of the ribosomal RNA (rRNA) operon that aminoglycosides target. ${ }^{36,52}$ This allows several single genetic mutations to cause high-level (MICs $>1,000 \mathrm{mg} / \mathrm{L}$ ) drug resistance to aminoglycosides. ${ }^{36,52}$ In addition to the inducible resistance mechanism to macrolides mentioned above, there is also the potential for a point mutation in the 23S rRNA peptidyl transferase region of MABc, which confers macrolide resistance (MICs $>4 \mathrm{mg} / \mathrm{L}$ ), most commonly in the setting of prior macrolide monotherapy. ${ }^{53}$

\section{Susceptibility Testing}

The CLSI currently recommends the broth microdilution minimal inhibitory concentration (MIC) method for determining the susceptibility of MABc using a panel of 10 antimicrobials (-Table 3). ${ }^{45}$ Agar tests, including the E-test, are not recommended because of inconsistency of results. ${ }^{54}$ It is important to note that there is no proven clinical correlation between MICs and treatment outcome for pulmonary MABc. ${ }^{1}$ There does appear to be a correlation between in vitro susceptibility and clinical response in skin and soft tissue infection, although this observation has not been prospectively confirmed. ${ }^{1}$ In general, amikacin, cefoxitin, imipenem, clofazimine, and macrolides (the last only in MABc organisms without an active erm gene) have the most reliably low MICs suggesting the highest chance of clinical activity, although with no antibiotic is this reliable enough to dispense with MIC testing (- Table 4). ${ }^{1,36}$

\section{Treatment Choice and Treatment Response}

Because of a paucity of prospective, controlled, or randomized treatment studies, most treatment recommendations for $\mathrm{MABc}$ disease rely heavily on small retrospective or observational datasets, extrapolation from the treatment of other mycobacterial organisms, in vitro studies, and expert opinion. ${ }^{1}$ In this context, individual patient response, treatment toxicity,

Table 4 Antibiotic susceptibility of MABC as defined by MIC (mg/L)

\begin{tabular}{|l|l|l|l|l|}
\hline Antibiotic & Studies & Number of subjects & MIC range (mod) (mg/L) & Percent susceptible $^{\mathrm{a}}$ \\
\hline Clarithromycin & 2 & $48-74$ & $0.03-16(0.03)$ & $83-99$ \\
\hline Cefoxitin & 2 & $48-74$ & $16-128(32)$ & $11-99$ \\
\hline Imipenem & 2 & $48-74$ & $1-64(8)$ & $8-55$ \\
\hline Ciprofloxacin & 2 & $48-74$ & $0.016-8(2)$ & $44-57$ \\
\hline Levofloxacin & 1 & 21 & $8-64(32)$ & Not reported \\
\hline Moxifloxacin & 1 & 21 & $2-32(16)$ & 73 \\
\hline Doxycycline & 1 & 20 & $2->128(>128)$ & 5 \\
\hline Minocycline & 1 & 20 & $0.25->64(>64)$ & 5 \\
\hline Tigecycline & 1 & 20 & $\leq 0.06-1(0.12)$ & 100 \\
\hline Linezolid & 1 & 98 & $0.5-128(32)$ & 23 \\
\hline Sulfamethoxazole & 2 & $48-74$ & $4-256(256)$ & $1-12$ \\
\hline Amikacin & 2 & $48-117$ & $0.25->128(2$ and 16$)$ & $87-94$ \\
\hline Tobramycin & 3 & $21-117$ & $4->128(8$ and 16) & $36-95$ \\
\hline Clofazimine & 1 & 117 & $0.25-1(0.5)$ & 99 \\
\hline
\end{tabular}

Note: Adapted from Nessar et al. ${ }^{36}$

${ }^{\text {a }}$ Susceptibility breakpoints as defined by Griffith et al ${ }^{1}$ and Woods et al. ${ }^{54}$ 
and overall goals of therapy are important considerations. That said, owing to the disease complexity and use of uncommon antimicrobials, expert recommendations and guidelines have an important role to play in management, a sobering concept given how infrequently even basic guidelines are followed for NTM disease. ${ }^{1,55}$ Below we have attempted to outline treatment considerations and recommendations for pulmonary $\mathrm{MABc}$ as well as specific considerations for the various antibiotics most frequently used. ${ }^{56}$ There are some general principles that should be followed, including prolonged therapy, an induction phase of therapy with a three- to four-drug regimen including one to two different active intravenous (IV) agents, and a suppressive phase which should involve at least two oral or inhaled antibiotics considered active based on drug susceptibilities, since most patients cannot tolerate 12 to 18 months of IV therapy. ${ }^{1}$

Pulmonary MABc disease is difficult to manage and treatment outcomes are generally poor. ${ }^{1,4}$ There is a clear difference in treatment response based on subspecies with subsp massiliense having significantly better treatment outcomes than subsp abscessus (-Table 5). This is almost certainly due to the ability to use macrolide-based therapy for massiliense, which allows a more effective overall regimen and less treatment-related toxicity. ${ }^{1,57,58}$ IV amikacin is generally the most active agent and is recommended as part of most treatment regimens if feasible from a renal and ototoxicity standpoint using three times per week (TIW) dosing. ${ }^{1,4}$ Generally, an IV BL (either imipenem or cefoxitin) should be added for the initial phase of therapy as well. ${ }^{1}$ Imipenem has a better toxicity profile than cefoxitin and older concerns about its efficacy have been somewhat refuted by newer in vitro data, so it is our preferred BL in most cases. ${ }^{36,59}$ At least 4 to 8 weeks of dual IV induction therapy is recommended to give the best chance of prolonged clinical response. ${ }^{1,15,58}$ In macrolide-susceptible isolates, an oral macrolide should be part of the treatment regimen, but even in nonsusceptible isolates, there may be a role for an oral macrolide given the benefits to airway inflammation and against other concurrent potential pathogens (see section Macrolides below). Clofazimine is often the only other oral antibiotic with a favorable susceptibility profile, although there are no rigorous clinical trials proving its efficacy. ${ }^{60,61}$ However, in vitro data and small case series suggest it could be a useful agent to add instead of or along with a macrolide. ${ }^{60,61}$ Given how difficult it is to obtain the recommended 12 months of negative sputum cultures for MABc lung disease, symptom and radiographic improvement are useful markers of treatment success. ${ }^{1}$

Because of the poor response to antibiotic treatment, in many cases surgical intervention in combination with antibiotic therapy holds the greatest chance of prolonged remission or cure, especially in cases where the areas of pulmonary infection are focal. ${ }^{62,63}$ Although most NTM lung surgery data are in pulmonary MAC, the surgical technique is similar for MABc. ${ }^{64,65}$ In pulmonary MAC, surgical intervention has been shown to be safe and effective, although there is not a large enough body of literature in $\mathrm{MABc}$ to prove it is equally safe. ${ }^{64,65}$ If surgery is pursued, we recommend aggressive antimicrobial therapy in the 4 to 8 weeks before surgery to lower the bacterial burden and geographic extent of infection before lung resection. We also strongly recommend this take place at a center surgically experienced in NTM lung disease.

\section{Specific Antimicrobials}

One of the key components of MABc treatment is the use of three or more antimicrobials in most treatment regimens to increase efficacy and decrease the development of antibiotic resistance. Thus, the interplay between different antibiotics is an important dynamic with synergy or enhanced abilities to protect each other from the development of resistance as key theoretical components of more effective regimens.

\section{Beta-lactams}

Although BLs are a mainstay in the treatment of many grampositive bacterial infections, most of the class has little utility against MABc because of its production of $\mathrm{Bla}_{\mathrm{MAB}}$, a broadspectrum $\beta$-lactamase that inactivates most BLs. ${ }^{66}$ Unfortunately, Bla $\mathrm{MABc}_{\mathrm{B}}$ is not effectively inhibited by the standard $\beta$-lactamase inhibitors clavulanate, tazobactam, and sulbactam. ${ }^{66}$ Imipenem and cefoxitin are more slowly hydrolyzed than other BLs, allowing them to maintain activity against many MABc isolates. ${ }^{66}$ Other carbapenems such as meropenem are not as active as imipenem, and in the treatment of MABc, imipenem is the carbapenem of choice. ${ }^{67}$ In vitro studies suggest that imipenem has lower relative MICs than cefoxitin, although there can be difficulties around the lack of reliability of imipenem MICs. ${ }^{1,59,68}$ Interestingly, in animal models, the new $\beta$-lactamase inhibitor, avibactam, effectively inhibits Bla $\mathrm{MABC}_{\mathrm{M}}$ potentially improving imipenem efficacy against these organisms and significantly reducing MICs against the new BL ceftaroline, although not enough to make ceftaroline useful in treatment. ${ }^{69-71}$ There is potential intracellular synergy between imipenem and amikacin that is not present with cefoxitin and amikacin, another argument for imipenem over cefoxitin since both drugs are often used in combination with an aminoglycoside. ${ }^{1,59,68}$ Although there are no comparative studies to date on the toxicity of imipenem versus cefoxitin, our experience has been that imipenem is also more tolerable over a prolonged treatment course. One nuance in using both antibiotics to treat $\mathrm{MABC}$ is that both are dosed every 12 hours in contrast to the every 8-hour or every 6-hour schedule on which they are dosed for most other infections. There does not appear to be utility to continuous infusion dosing with cefoxitin and it is impractical with imipenem because of drug stability. ${ }^{72}$

\section{Intravenous Amikacin}

IV amikacin is generally considered the most active antibiotic available for the treatment of MABc infections. ${ }^{1,5,36}$ Microbial killing due to IV amikacin is believed to be linked to peak serum-to-MIC $\left(C_{\max } / \mathrm{MIC}\right)$ ratios with the optimal ratio estimated as 3 to $5 .{ }^{1,73}$ ATS treatment guidelines suggest a dose of 10 to $15 \mathrm{mg} / \mathrm{kg}$, with the lower dose of $10 \mathrm{mg} / \mathrm{kg}$ recommended in the elderly or those on prolonged therapy (situations applying to most patients). ${ }^{1,36}$ The concern with IV amikacin is drug toxicity with ototoxicity/vestibular and renal toxicity 


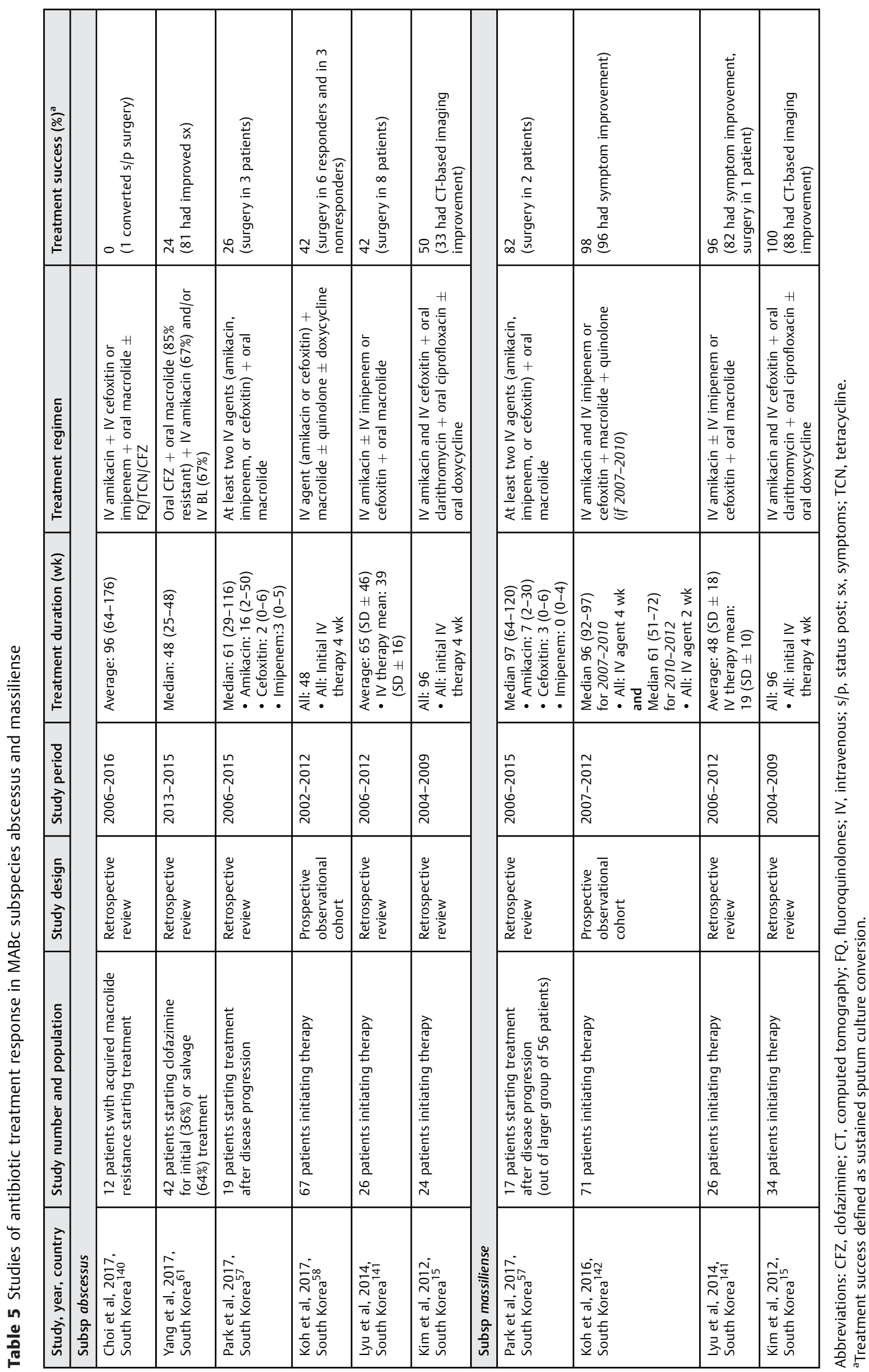


being the primary considerations, although liver function testing abnormalities also occur. In general, ototoxicity seems to be irreversible and related to cumulative dose and higher trough levels, while renal toxicity is usually reversible with drug discontinuation/dose reduction and vestibular toxicity is often transient, regardless of dosing change. ${ }^{74-77}$ Toxicity seems to increase with treatment courses longer than 8 to 12 weeks. ${ }^{77}$ It is controversial whether daily versus TIW dosing is more efficacious and there are no good comparative data. ${ }^{1}$ However, there are comparative data showing lower toxicity rates with TIW dosing, so this is generally our recommended strategy. There does not appear to be any benefit to dosing more than once a day as is done with many other bacterial infections, so we strongly recommend against this for MABc. ${ }^{76}$ Given the toxicity, close monitoring is important, and we recommend baseline and monthly audiology testing as well as at least a complete metabolic panel and complete blood count every other week as well confirming correct amikacin dose via estimation of serum-to-MIC levels as above. In vitro data suggest that subinhibitory amikacin levels may be not just less effective but also harmful by causing physiologic changes to the organism that make it more robust and virulent. ${ }^{78,79}$ Even more concerning, in vitro data suggest that MABc organisms with a functional erm gene may be able to induce amikacin resistance on macrolide exposure through a WhiB7-dependent network of resistance genes. ${ }^{80}$ These data need additional confirmatory work and in vivo evaluation, but it is worrisome given the prevalence of both macrolides and amikacin in many regimens and raises the question of whether this contributes to the poor outcomes for subsp abscessus where a functional erm gene is frequently present and macrolides still often used.

\section{Inhaled Amikacin}

Since the most limiting feature of IV amikacin is drug toxicity, it is not surprising that there has been interest in whether an inhaled formulation of that drug has efficacy for treating MABC pulmonary infections. A retrospective study of 15 patients suggested that inhaled amikacin led to improved symptoms and culture responses in a notable minority of the cases, but that increasing toxicity limited doses higher than $250 \mathrm{mg} /$ day. ${ }^{81}$ Subsequent animal model work suggested a new liposomal form of inhaled amikacin might be effective for the treatment of $\mathrm{MABc}$ (as well as MAC). ${ }^{82}$ This led to one of the few randomized controlled trials in this field using inhaled liposomal amikacin for NTM lung disease which showed improvement in the intervention arm, although only one-third of the 89 patients were $\mathrm{MABc}$ and their response was difficult to observe in the only 3-month-long study. ${ }^{83}$ There is currently an ongoing openlabel trial evaluating the liposomal formulation in subsp abscessus lung infection (NCT03038178), which may shed more light on this issue.

\section{Macrolides}

Antibiotics in the macrolide class (clarithromycin, azithromycin, erythromycin) have traditionally been the most important agents in the treatment of NTM infections. However, as mentioned above, their use in the treatment of MABc infections is much more complicated because of inducible macrolide resistance conferred by a functional erm gene. Selection of macrolide resistance is sometimes even less straightforward than presence or absence of a functional erm gene as certain subsp abscessus sequevars and subsp bolletii appear to have other mechanisms that cause macrolide nonsusceptibility. ${ }^{84}$ Although, traditionally, clarithromycin (CLARI) has been the macrolide of choice, data suggest the newer macrolide azithromycin (AZI) is more active, easier to tolerate, and causes somewhat less activation of the inducible macrolide resistance mechanism. ${ }^{85}$ AZI has the added benefit of fewer drug-drug interactions as well as daily dosing instead of twice-daily dosing with CLARI, and for these reasons, it should be considered the macrolide of choice for $\mathrm{MABc}^{86}$ As mentioned, there is concern about potential antagonism by macrolides and amikacin in MABc strains with an active erm gene, as well as with fluoroquinolones specifically in subsp abscessus (discussed in more detail in next section). ${ }^{80}$ Interestingly, for subsp massiliense, there is possible in vitro synergy between macrolides (CLARI was macrolide studied) and the fluoroquinolone moxifloxacin as well as the tetracycline tigecycliane, another example of the different drug response phenotype of this subspecies. ${ }^{87}$ One other difficulty created by macrolide and aminoglycoside combination therapy is that macrolides can rarely cause sensorineural ototoxicity, which in a small number of cases can be irreversible. ${ }^{88}$ This effect can start after limited macrolide exposure and can make it difficult to know whether it is the aminoglycoside or the macrolide causing ototoxicity. ${ }^{88}$ The anti-inflammatory properties that macrolides, particularly AZI, possess have been well documented as part of their benefit against airway exacerbations in many different lung diseases states including non-CF bronchiectasis. ${ }^{89,90}$ It is possible as part of a long-term regimen that they benefit to MABc pulmonary infections in this way, but this has not been proven and, when used in this fashion, they should not be counted as an active $\mathrm{MABC}$ antibiotics, unless the organism is known to be macrolide susceptible.

\section{Clofazimine}

Clofazimine (CFZ) is an older antibiotic that has long been used in treatment of the mycobacterial infections caused by Mycobacterium leprae and more recently included in some new regimens for drug-resistant tuberculosis. ${ }^{91,92}$ CFZ MICs to $\mathrm{MABc}$ are typically very low and make it the most reliably active in vitro oral antibiotic option available ( - Table 3). ${ }^{36,93} \mathrm{In}$ the context of MABc therapy, CFZ also has the attractive property of in vitro synergy with amikacin, which seems to decrease MICs to both by four- to eightfold. ${ }^{93-95}$ It also appears to have some synergy with macrolides. ${ }^{95}$ These findings make CFZ a potentially useful agent in MABc therapy, and it is used off-label frequently. ${ }^{1}$ Two recent studies, one retrospective cohort (15 patients for initial therapy and 27 patients for salvage therapy) and one prospective observational cohort (54 patients), used CFZ as part of a multidrug regimen for MABc pulmonary disease and showed promising symptom and culture-based outcomes with relatively minimal rates of treatment-limiting side effects. ${ }^{60,61}$ Given these data, we recommend CFZ as an important part of many MABc treatment 
regimens, especially when there are no other active oral agents. Although skin discoloration is the most well-known of CFZ side effects, the most common treatment-limiting side effects are gastrointestinal in nature. ${ }^{60,61} \mathrm{CFZ}$ has a very long half-life of roughly 50 to 75 days and a provider should assume it takes around 2 months before the drug reaches therapeutically active levels. ${ }^{96,97} \mathrm{CFZ}$ has not been available through traditional pharmaceutical distribution since 2004 and can only been obtained either via investigational new drug (IND) directly from the manufacturer (Novartis) or through individual IRBapproved IND to the Federal Drug Administration (FDA). There is an ongoing placebo-controlled trial funded by the FDA looking at the use of CFZ in MAC pulmonary disease, which should shed further light on the drug's use in pulmonary NTM disease (NCT02968212).

\section{Fluoroquinolones}

Fluoroquinolones (FQs) are an attractive option for MABc therapy because of their excellent oral bioavailability and good performance in the treatment of other mycobacterial infections, especially tuberculosis. However, there are a couple of in vitro considerations that somewhat mitigate this optimism for MABc as resistance to FQs has been shown to develop quickly during monotherapy, and there is evidence of antagonism between macrolides and FQs in many subsp abscessus isolates. ${ }^{98-100}$ As previously mentioned, FQs are used in many other clinical diseases and ubiquitously in agriculture, and this may contribute to the fact that high percentage of isolates are FQ resistant, and thus the drug class should not be relied on without susceptibility testing on a recent isolate. ${ }^{101}$ That said, FQs have been used as part of combination therapy in a couple of retrospective studies and there is probably a role for their use when MIC testing shows favorable results. ${ }^{9,102}$ Given the concerning in vitro studies with FQ monotherapy and potential antagonism with macrolides for subsp abscessus (much more with CLARI than AZI), we strongly recommend against monotherapy or dual therapy with only CLARI as part of a treatment or suppressive regimen. ${ }^{98-100}$ When used for gram-positive infections such as mycobacterial infections, moxifloxacin is generally the most active drug in the class and is the FQ we recommend if these drugs are to be used for MABc therapy. Since therapy is often prolonged and the patient population often receives intermittent steroids or other QT prolonging agents, care should be taken to monitor for both QT prolongation and arthropathies when using FQs for MABc therapy.

\section{Tigecycline}

The tetracycline (TCN) drug class has broad antibacterial activity including against some mycobacteria. The newer IV $\mathrm{TCN}$, tigecycline, appears to have particular in vitro efficacy against rapid-growing mycobacteria including MABc compared with other TCNs and to its own activity against slowgrowing mycobacteria. ${ }^{103,104}$ Here again, synergy with other drugs is an important consideration, and in vitro data suggest that tigecycline may have synergy with macrolides, although it does not appear to have this benefit with aminoglycosides. ${ }^{105}$ Clinical data are limited, but one study that used tigecycline as part of a salvage therapy regimen in 52 patients with $\mathrm{MABc} / M$. chelonae infection (roughly $75 \%$ were MABc) showed clinical improvement in $62 \%$ of patients who received more than 1 month of therapy out of the subset of 36 patients who had clinically evaluated outcomes. ${ }^{106}$ Adverse drug events were common, and although it is unclear which antibiotic in the treatment was the cause of the symptoms, many of these events were gastrointestinal in nature (nausea $>$ vomiting $>$ diarrhea $>$ anorexia), side effects particularly common with tigecycline. ${ }^{106}$ The side effect profile was more pronounced at higher doses and mitigated by preinfusion treatment with antiemetics; hence, in pulmonary disease we recommend dosing at $50 \mathrm{mg} /$ day and using preinfusion antiemetics when the tigecycline is used. ${ }^{106}$ When used in this manner, we recommend tigecycline as an alternative IV option if either amikacin or imipenem/cefoxitin is not possible based on susceptibility testing or other factors.

\section{Oxazolidinones}

The oxazolidinone drug class, which includes linezolid (LZD) and tedizolid (TZD), acts by inhibiting protein synthesis at the 50s ribosomal subunit and has the attractive properties of good oral bioavailability and tissue penetration. ${ }^{107}$ LZD has been studied extensively for the treatment of tuberculosis and seems effective and more tolerable at doses of either 300 or $600 \mathrm{mg}$ daily compared with the $600 \mathrm{mg}$ twice daily dose used for nonmycobacterial infections. ${ }^{108,109}$ Although the option of an active oral agent is appealing, clinical data for the oxazolidinones in the treatment of MABC are at the level of case reports, and MICs to a majority of $\mathrm{MABc}$ isolates are much higher than for TB, although good in vitro activity can be seen in a minority of isolates. ${ }^{1,110,111}$ LZD appears to have in vitro synergy with amikacin and macrolides in a proportion of isolates, although it may have potential antagonism with both cefoxitin and moxifloxacin. ${ }^{87,111}$ TZD may have better MABc activity than LZD with lower MICs on in vitro testing-however, interpretive breakpoints do not yet exist for TZD. ${ }^{110}$ Unfortunately, toxicity with LZD appears to be common in prolonged treatment courses even at daily dosing and most individuals cannot tolerate treatment for more than 4 to 6 months. ${ }^{112}$ Peripheral neuropathy, not mitigated by pyridoxine, is the most common side effect seen in roughly $25 \%$ of cases. ${ }^{112}$ In general, we do not recommend the oxazolidinones as part of first-line regimens given the paucity of clinical data. However, they may have a role for periods of time when supported by favorable susceptibility testing.

\section{Bedaquiline}

Bedaquiline is a novel diarylquinoline antibiotic that potently inhibits ATP synthase in mycobacteria, has good bioavailability, and is now FDA approved for the treatment of drugresistant tuberculosis. ${ }^{113,114}$ It appears to have a broad range of in vitro activity against NTM isolates including members of the MABc. ${ }^{115,116}$ Specifically, in this complex, roughly 70 to $80 \%$ of isolates appear to be susceptible based on in vitro testing and estimated, but not formally established, breakpoints. ${ }^{115}$ Data for NTM disease are limited, but safety data can 
probably be approximated from the tuberculosis literature and suggest that nausea, hepatotoxicity, and QT prolongation are the primary drug-related adverse events. ${ }^{117}$ Clinical efficacy data are very limited, with the primary clinical study published to date (a 10-patient case series: 6 MAC lung disease and 4 MABc lung disease) using the $400 \mathrm{mg}$ daily followed by $200 \mathrm{mg}$ TIW dosing that has been used in the tuberculosis trials. ${ }^{118}$ This study suggested some microbiologic response based on semiquantitative sputum cultures, although it also demonstrated high rates of nonsevere side effects. ${ }^{118}$ Given these limited data, we recommend considering bedaquiline in alternative or salvage therapy regimens when other oral antibiotic options are limited, although ability to effectively utilize the medication will likely be constrained by cost and drug access in some cases.

\section{Specific Disease State Treatment Considerations}

\section{Cystic Fibrosis}

CF is an important underlying predisposition for pulmonary NTM infection and disease because of the significant bronchiectasis and impairment to pulmonary immune defenses that $\mathrm{CF}$ confers. As a result, a high percentage of individuals with $\mathrm{CF}$ have pulmonary colonization with an NTM, ranging from 5 to $30 \%$ depending on the case series. ${ }^{18,26,119-121}$ MABc is the second most common NTM after MAC in this setting, but for reasons that are unclear its incidence is rising, unlike MAC incidence, which is flat. Most NTMs can cause invasive disease in $\mathrm{CF}$, leading to more rapid decline in lung function and at times to NTM-related mortality, with MABc seeming to contribute to a more deleterious course than other NTMs. ${ }^{121-123}$ Although there is concern for human transmission in MABc outbreaks at $\mathrm{CF}$ centers, the limited genetic diversity in the complex makes genetic clustering harder to use as an outbreak marker; therefore, while there is concern about this issue, it is generally considered an unresolved concern. ${ }^{25,124}$ Despite the importance of $\mathrm{MABc}$ in $\mathrm{CF}$, there are no randomized controlled trials or highly controlled studies looking at the effect of antimicrobial therapy versus no therapy or comparing different antimicrobial regimens in $\mathrm{CF}$, and treatment guidance is limited to small, retrospective, single-center case series. ${ }^{123}$

One common practice in CF management, the use of prophylactic azithromycin to prevent pulmonary exacerbations, does appear to be protective against the development of incident NTM lung disease, although it is unclear if this applies to MABc, with some datasets suggesting lower MABc prevalence and others suggesting the NTM prevalence shifting toward $\mathrm{MABc}{ }^{125,126}$ One concern given the antibiotic exposure in the $\mathrm{CF}$ population is that their MABc isolates may in general be more resistant than in non-CF cases, but this has not been clearly borne out by data. ${ }^{127}$ Once MABc pulmonary disease develops, the same principles that apply to $\mathrm{MABc}$ treatment in the non-CF population should be applied. ${ }^{1}$ Similar to the non-CF setting, the subsp massiliense appears to be associated with better treatment outcomes than subsp abscessus. ${ }^{128}$ Given the young age of this patient population, repeated treatment courses or long-term sup- pression is more likely to be needed because of the many years of potential for reinfection and/or relapse. In the $\mathrm{CF}$ population, there are even more issues with concurrent pulmonary disease caused by other NTMs, especially MAC, as well as other respiratory pathogens such as Staphylococcus aureus, Pseudomonas, and Aspergillus. ${ }^{28,123}$ Unfortunately, although surgery is an attractive option for difficult MABc lung disease cases in other patient populations, there may be additional risks to this intervention in the $\mathrm{CF}$ leading to less favorable outcomes. ${ }^{30}$ Another difficulty is that for many more advanced CF cases, the only management strategy available is lung transplant, but as is discussed more in the subsequent section, at many centers lung transplant is not offered when there is concomitant MABc infection.

\section{Treatment Considerations Specific to Lung Transplant Recipients}

Lung transplant raises four unique and complicated considerations in relation to MABc infection: (1) pretransplant management, (2) viability of lung transplant in the setting of MABc lung disease, (3) risk of posttransplant MABc lung disease, and (4) management of posttransplant MABc lung disease.

In general, pretransplant management is the same as general MABc management mentioned above, although we favor the most aggressive possible antimicrobial therapy in the immediate pretransplant period. One important consideration for $\mathrm{MABc}$ lung disease is that many centers consider MABc infection a contraindication for lung transplant, which precludes CF patients with end-stage disease from having a transplant, which is the only curative management strategy for their CF disease. ${ }^{129}$ This contraindication is largely based on expert opinion and the literature to support this practice is limited. ${ }^{130,131}$ In fact, several more recent small retrospective series suggest that outcomes may not be worse in those with pretransplant pulmonary cultures showing $\mathrm{MABc}$, although there seems to be a higher rate of treatable posttransplant surgical site infections with MABc in these hosts. ${ }^{129,132-134}$

Lung transplant is the solid organ transplant with the highest risk of posttransplant NTM lung disease. ${ }^{135,136}$ There does seem to be a significant rate of transient and clinically insignificant colonization in the posttransplant period, so being post-lung transplant does not inherently change the dynamic that not all positive pulmonary NTM cultures require treatment and transient colonization does not seem to portend a worse posttransplant outcome. ${ }^{137,138}$ MABc appears to be the most common posttransplant cause of NTM lung disease with a risk of infection highest in the first 3 years after transplant. ${ }^{3,136}$ There seems to be a trend toward worse posttransplant survival in cases that develop NTM lung disease. However, it is not clear if this trend is further worsened in those whose lung disease is caused by members of $\mathrm{MABc}$, and there is evidence suggesting that posttransplant MABc infection can be successfully managed with prolonged aggressive therapy. 3,129,132-134,136,139 Treatment is no different than in the nontransplant population, although regimen choice may be more difficult and closer toxicity monitoring needed because of potential drug interactions with transplant medications. ${ }^{1}$ We recommend the same criteria for $\mathrm{MABc}$ disease in the posttransplant setting as the 
nontransplant population but would initiate aggressive MABc therapy if a patient meets criteria for MABc disease without any period of observation off therapy. We recommend prolonged therapy along with multidrug IV induction therapy and would generally err on the side of treating longer than the nontransplant population because of the underlying immunodeficiencies. Finally, we would be more inclined to continue some form of chronic suppressive therapy in this population if there is an oral regimen with tolerable side effects and toxicities, although this is not needed in all cases.

\section{Conclusion}

The MABc organisms are increasingly recognized as a pulmonary pathogen that requires treatment in some individuals. Our belief is that most infected individuals eventually progress to disease, although natural history studies to definitively substantiate this are lacking. The MABc poses significant and unique treatment challenges because of its extensive drug resistance profile and propensity for persistence. The antibiotic regimens used for this disease involve both antibiotics less commonly used by pulmonary or infectious diseases practitioners and those that require prolonged use and careful monitoring. Response to therapy is highly dependent on MABc subspecies, and even with optimal therapy, some organisms in the MABc still have suboptimal antibiotic treatment outcomes. In settings of suboptimal response, lung-resection surgery is a consideration in management. While MABc disease is both more common and problematic in the unique populations of $\mathrm{CF}$ and lung transplant recipients, the organism can still be managed in these settings. Because of the complexity of this disease, expert consultation is a recommended part of management. Additional research is desperately needed to better understand disease pathogenesis, discover novel antibiotic therapies, and identify optimal treatment strategies, with one of the most important challenges being the identification whether in vitro susceptibility data predict clinical response.

\section{Disclosure}

Luke Strnad is the guarantor of this article.

Roles:

Literature review: Luke Strnad.

Writing: Luke Strnad, Kevin Winthrop.

Financial Support

None.

Conflict of Interest

Kevin Winthrop received consultant and research support from Insmed, Inc.

\section{References}

1 Griffith DE, Aksamit T, Brown-Elliott BA, et al; ATS Mycobacterial Diseases Subcommittee; American Thoracic Society; Infectious Disease Society of America. An official ATS/IDSA statement: diagnosis, treatment, and prevention of nontuberculous mycobacterial diseases. Am J Respir Crit Care Med 2007;175(04):367-416
2 Yu X, Liu P, Liu G, et al. The prevalence of non-tuberculous mycobacterial infections in mainland China: Systematic review and meta-analysis. J Infect 2016;73(06):558-567

3 Shah SK, McAnally KJ, Seoane L, et al. Analysis of pulmonary nontuberculous mycobacterial infections after lung transplantation. Transpl Infect Dis 2016;18(04):585-591

4 Koh WJ, Stout JE, Yew WW. Advances in the management of pulmonary disease due to Mycobacterium abscessus complex. Int J Tuberc Lung Dis 2014;18(10):1141-1148

5 Lee MR, Sheng WH, Hung CC, Yu CJ, Lee LN, Hsueh PR. Mycobacterium abscessus complex infections in humans. Emerg Infect Dis 2015;21(09):1638-1646

6 Kusunoki S, Ezaki T. Proposal of Mycobacterium peregrinum sp. nov., nom. rev., and elevation of Mycobacterium chelonae subsp. abscessus (Kubica et al.) to species status: Mycobacterium abscessus comb. nov. Int J Syst Bacteriol 1992;42(02):240-245

7 Thomson R, Tolson C, Sidjabat H, Huygens F, Hargreaves M. Mycobacterium abscessus isolated from municipal water - a potential source of human infection. BMC Infect Dis 2013;13:241

8 De Groote MA, Huitt G. Infections due to rapidly growing mycobacteria. Clin Infect Dis 2006;42(12):1756-1763

9 Jarand J, Levin A, Zhang L, Huitt G, Mitchell JD, Daley CL. Clinical and microbiologic outcomes in patients receiving treatment for Mycobacterium abscessus pulmonary disease. Clin Infect Dis 2011;52(05):565-571

10 Yoshida S, Tsuyuguchi K, Kobayashi T, et al. Association between sequevar and antibiotic treatment outcome in patients with Mycobacterium abscessus complex infections in Japan. J Med Microbiol 2018;67(01):74-82

11 Greendyke R, Byrd TF. Differential antibiotic susceptibility of Mycobacterium abscessus variants in biofilms and macrophages compared to that of planktonic bacteria. Antimicrob Agents Chemother 2008;52(06):2019-2026

12 Kim HY, Kim BJ, Kook Y, et al. Mycobacterium massiliense is differentiated from Mycobacterium abscessus and Mycobacterium bolletii by erythromycin ribosome methyltransferase gene (erm) and clarithromycin susceptibility patterns. Microbiol Immunol 2010;54(06):347-353

13 Bastian S, Veziris N, Roux AL, et al. Assessment of clarithromycin susceptibility in strains belonging to the Mycobacterium abscessus group by erm(41) and rrl sequencing. Antimicrob Agents Chemother 2011;55(02):775-781

14 Kim SY, Shin SJ, Jeong BH, Koh WJ. Successful antibiotic treatment of pulmonary disease caused by Mycobacterium abscessus subsp. abscessus with C-to-T mutation at position 19 in erm(41) gene: case report. BMC Infect Dis 2016;16:207

$15 \mathrm{Kim}$ HS, Lee KS, Koh WJ, et al. Serial CT findings of Mycobacterium massiliense pulmonary disease compared with Mycobacterium abscessus disease after treatment with antibiotic therapy. Radiology 2012;263(01):260-270

16 Shin SJ, Choi GE, Cho SN, et al. Mycobacterial genotypes are associated with clinical manifestation and progression of lung disease caused by Mycobacterium abscessus and Mycobacterium massiliense. Clin Infect Dis 2013;57(01):32-39

17 Diel R, Ringshausen F, Richter E, Welker L, Schmitz J, Nienhaus A. Microbiological and clinical outcomes of treating non-Mycobacterium avium complex nontuberculous mycobacterial pulmonary disease: a systematic review and meta-analysis. Chest 2017; 152(01):120-142

18 Prevots DR, Shaw PA, Strickland D, et al. Nontuberculous mycobacterial lung disease prevalence at four integrated health care delivery systems. Am J Respir Crit Care Med 2010;182(07): 970-976

19 Hoefsloot W, van Ingen J, Andrejak C, et al; Nontuberculous Mycobacteria Network European Trials Group. The geographic diversity of nontuberculous mycobacteria isolated from pulmonary samples: an NTM-NET collaborative study. Eur Respir J 2013;42(06):1604-1613 
20 Nagano H, Kinjo T, Nei Y, Yamashiro S, Fujita J, Kishaba T. Causative species of nontuberculous mycobacterial lung disease and comparative investigation on clinical features of Mycobacterium abscessus complex disease: a retrospective analysis for two major hospitals in a subtropical region of Japan. PLoS One 2017;12(10):e0186826

21 Lee MR, Keng LT, Shu CC, et al. Risk factors for Mycobacterium chelonae-abscessus pulmonary disease persistence and deterioration. J Infect 2012;64(02):228-230

22 van Ingen J, de Zwaan R, Dekhuijzen RP, Boeree MJ, van Soolingen D. Clinical relevance of Mycobacterium chelonae-abscessus group isolation in 95 patients. J Infect 2009;59(05):324-331

23 Koh WJ, Jeon K, Lee NY, et al. Clinical significance of differentiation of Mycobacterium massiliense from Mycobacterium abscessus. Am J Respir Crit Care Med 2011;183(03):405-410

24 Roux AL, Catherinot E, Ripoll F, et al; Jean-Louis Herrmann for the OMA Group. Multicenter study of prevalence of nontuberculous mycobacteria in patients with cystic fibrosis in france. J Clin Microbiol 2009;47(12):4124-4128

25 Aitken ML, Limaye A, Pottinger P, et al. Respiratory outbreak of Mycobacterium abscessus subspecies massiliense in a lung transplant and cystic fibrosis center. Am J Respir Crit Care Med 2012;185(02):231-232

26 Olivier KN, Weber DJ, Wallace RJ Jr, et al; Nontuberculous Mycobacteria in Cystic Fibrosis Study Group. Nontuberculous mycobacteria. I: multicenter prevalence study in cystic fibrosis. Am J Respir Crit Care Med 2003;167(06):828-834

27 Czaja CA, Levin AR, Cox CW, Vargas D, Daley CL, Cott GR. Improvement in quality of life after therapy for Mycobacterium abscessus group lung infection. A prospective cohort study. Ann Am Thorac Soc 2016;13(01):40-48

28 Surette MG. The cystic fibrosis lung microbiome. Ann Am Thorac Soc 2014;11(Suppl 1):S61-S65

29 Birmes FS, Wolf T, Kohl TA, et al. Mycobacterium abscessus subsp. abscessus is capable of degrading Pseudomonas aeruginosa quinolone signals. Front Microbiol 2017;8:339

30 Griffith DE, Girard WM, Wallace RJ Jr. Clinical features of pulmonary disease caused by rapidly growing mycobacteria. An analysis of 154 patients. Am Rev Respir Dis 1993;147(05):1271-1278

31 Satta G, McHugh TD, Mountford J, Abubakar I, Lipman M. Managing pulmonary nontuberculous mycobacterial infection. time for a patient-centered approach. Ann Am Thorac Soc 2014; 11(01):117-121

32 Chung MJ, Lee KS, Koh WJ, et al. Thin-section CT findings of nontuberculous mycobacterial pulmonary diseases: comparison between Mycobacterium avium-intracellulare complex and Mycobacterium abscessus infection. J Korean Med Sci 2005;20 (05):777-783

33 Griffith DE, Philley JV, Brown-Elliott BA, et al. The significance of Mycobacterium abscessus subspecies abscessus isolation during Mycobacterium avium complex lung disease therapy. Chest 2015;147(05):1369-1375

34 Shallom SJ, Gardina PJ, Myers TG, et al. New rapid scheme for distinguishing the subspecies of the Mycobacterium abscessus group and identifying Mycobacterium massiliense isolates with inducible clarithromycin resistance. J Clin Microbiol 2013;51 (09):2943-2949

35 Nakanaga K, Sekizuka T, Fukano H, et al. Discrimination of Mycobacterium abscessus subsp. massiliense from Mycobacterium abscessus subsp. abscessus in clinical isolates by multiplex PCR. J Clin Microbiol 2014;52(01):251-259

36 Nessar R, Cambau E, Reyrat JM, Murray A, Gicquel B. Mycobacterium abscessus: a new antibiotic nightmare. J Antimicrob Chemother 2012;67(04):810-818

37 Brennan PJ, Nikaido H. The envelope of mycobacteria. Annu Rev Biochem 1995;64:29-63

38 Jarlier V, Nikaido H. Permeability barrier to hydrophilic solutes in Mycobacterium chelonei. J Bacteriol 1990;172(03):1418-1423
39 Nguyen L, Thompson CJ. Foundations of antibiotic resistance in bacterial physiology: the mycobacterial paradigm. Trends Microbiol 2006;14(07):304-312

40 Malcolm KC, Nichols EM, Caceres SM, et al. Mycobacterium abscessus induces a limited pattern of neutrophil activation that promotes pathogen survival. PLoS One 2013;8(02):e57402

41 Qvist T, Eickhardt S, Kragh KN, et al. Chronic pulmonary disease with Mycobacterium abscessus complex is a biofilm infection. Eur Respir J 2015;46(06):1823-1826

42 Fennelly KP, Ojano-Dirain C, Yang Q, et al. Biofilm formation by Mycobacterium abscessus in a lung cavity. Am J Respir Crit Care Med 2016;193(06):692-693

43 Ripoll F, Pasek S, Schenowitz C, et al. Non mycobacterial virulence genes in the genome of the emerging pathogen Mycobacterium abscessus. PLoS One 2009;4(06):e5660

44 Nash KA, Brown-Elliott BA, Wallace RJ Jr. A novel gene, erm (41), confers inducible macrolide resistance to clinical isolates of Mycobacterium abscessus but is absent from Mycobacterium chelonae. Antimicrob Agents Chemother 2009;53(04): 1367-1376

45 Clinical and Laboratory Standards Institute. Susceptibility Testing of Mycobacteria, Nocardiae, and Other Aerobic Actinomycetes. 2nd ed. Wayne, PA: Clinical and Laboratory Standards Institute (CLSI); 2011

46 Yoshida S, Tsuyuguchi K, Suzuki K, et al. Further isolation of Mycobacterium abscessus subsp. abscessus and subsp. bolletii in different regions of Japan and susceptibility of these isolates to antimicrobial agents. Int J Antimicrob Agents 2013;42(03): 226-231

47 Alcaide F, Pfyffer GE, Telenti A. Role of embB in natural and acquired resistance to ethambutol in mycobacteria. Antimicrob Agents Chemother 1997;41(10):2270-2273

48 Guillemin I, Jarlier V, Cambau E. Correlation between quinolone susceptibility patterns and sequences in the A and B subunits of DNA gyrase in mycobacteria. Antimicrob Agents Chemother 1998;42(08):2084-2088

49 Forsberg KJ, Reyes A, Wang B, Selleck EM, Sommer MO, Dantas G. The shared antibiotic resistome of soil bacteria and human pathogens. Science 2012;337(6098):1107-1111

50 Hollis A, Ahmed Z. Preserving antibiotics, rationally. N Engl J Med 2013;369(26):2474-2476

51 Van Boeckel TP, Brower C, Gilbert M, et al. Global trends in antimicrobial use in food animals. Proc Natl Acad Sci U S A 2015; 112(18):5649-5654

52 Prammananan T, Sander P, Brown BA, et al. A single $16 \mathrm{~S}$ ribosomal RNA substitution is responsible for resistance to amikacin and other 2-deoxystreptamine aminoglycosides in Mycobacterium abscessus and Mycobacterium chelonae. J Infect Dis 1998; 177(06):1573-1581

53 Wallace RJ Jr, Meier A, Brown BA, et al. Genetic basis for clarithromycin resistance among isolates of Mycobacterium chelonae and Mycobacterium abscessus. Antimicrob Agents Chemother 1996;40(07):1676-1681

54 Woods GL, Bergmann JS, Witebsky FG, et al. Multisite reproducibility of Etest for susceptibility testing of Mycobacterium abscessus, Mycobacterium chelonae, and Mycobacterium fortuitum. J Clin Microbiol 2000;38(02):656-661

55 Adjemian J, Prevots DR, Gallagher J, Heap K, Gupta R, Griffith D. Lack of adherence to evidence-based treatment guidelines for nontuberculous mycobacterial lung disease. Ann Am Thorac Soc 2014;11(01):9-16

56 Novosad SA, Beekmann SE, Polgreen PM, Mackey K, Winthrop KL; M. abscessus Study Team. Treatment of Mycobacterium abscessus Infection. Emerg Infect Dis 2016;22(03):511-514

57 Park J, Cho J, Lee CH, Han SK, Yim JJ. Progression and treatment outcomes of lung disease caused by Mycobacterium abscessus and Mycobacterium massiliense. Clin Infect Dis 2017;64(03): 301-308 
58 Koh WJ, Jeong BH, Kim SY, et al. Mycobacterial characteristics and treatment outcomes in Mycobacterium abscessus lung disease. Clin Infect Dis 2017;64(03):309-316

59 Lavollay M, Dubée V, Heym B, et al. In vitro activity of cefoxitin and imipenem against Mycobacterium abscessus complex. Clin Microbiol Infect 2014;20(05):0297-0300

60 Martiniano SL, Wagner BD, Levin A, Nick JA, Sagel SD, Daley CL. Safety and effectiveness of clofazimine for primary and refractory nontuberculous mycobacterial infection. Chest 2017;152 (04):800-809

61 Yang B, Jhun BW, Moon SM, et al. Clofazimine-containing regimen for the treatment of Mycobacterium abscessus lung disease. Antimicrob Agents Chemother 2017;61(06):61

62 Koh WJ, Kim YH, Kwon OJ, et al. Surgical treatment of pulmonary diseases due to nontuberculous mycobacteria. J Korean Med Sci 2008;23(03):397-401

63 Kang HK, Park HY, Kim D, et al. Treatment outcomes of adjuvant resectional surgery for nontuberculous mycobacterial lung disease. BMC Infect Dis 2015;15:76

64 Mitchell JD, Bishop A, Cafaro A, Weyant MJ, Pomerantz M. Anatomic lung resection for nontuberculous mycobacterial disease. Ann Thorac Surg 2008;85(06):1887-1892, discussion 1892-1893

65 Yu JA, Pomerantz M, Bishop A, Weyant MJ, Mitchell JD. Lady Windermere revisited: treatment with thoracoscopic lobectomy/segmentectomy for right middle lobe and lingular bronchiectasis associated with non-tuberculous mycobacterial disease. Eur J Cardiothorac Surg 2011;40(03):671-675

66 Soroka D, Dubée V, Soulier-Escrihuela O, et al. Characterization of broad-spectrum Mycobacterium abscessus class A B-lactamase. J Antimicrob Chemother 2014;69(03):691-696

67 Brown-Elliott BA, Killingley J, Vasireddy S, Bridge L, Wallace RJ Jr. In vitro comparison of ertapenem, meropenem, and imipenem against isolates of rapidly growing mycobacteria and nocardia by use of broth microdilution and Etest. J Clin Microbiol 2016;54 (06):1586-1592

68 Lefebvre AL, Dubée V, Cortes M, Dorchêne D, Arthur M, Mainardi $\mathrm{JL}$. Bactericidal and intracellular activity of $\beta$-lactams against Mycobacterium abscessus. J Antimicrob Chemother 2016;71 (06):1556-1563

69 Dubée V, Bernut A, Cortes $M$, et al. $\beta$-Lactamase inhibition by avibactam in Mycobacterium abscessus. J Antimicrob Chemother 2015;70(04):1051-1058

70 Dubée V, Soroka D, Cortes $\mathrm{M}$, et al. Impact of $\beta$-lactamase inhibition on the activity of ceftaroline against Mycobacterium tuberculosis and Mycobacterium abscessus. Antimicrob Agents Chemother 2015;59(05):2938-2941

71 Lefebvre AL, Le Moigne $\mathrm{V}$, Bernut $A$, et al. Inhibition of the $\beta$ lactamase Bla $_{\mathrm{Mab}}$ by avibactam improves the in vitro and in vivo efficacy of imipenem against Mycobacterium abscessus. Antimicrob Agents Chemother 2017;61(04):61

72 Czaja CA, Levin A, Moridani M, Krank JL, Curran-Everett D, Anderson PL. Cefoxitin continuous infusion for lung infection caused by the Mycobacterium abscessus group. Antimicrob Agents Chemother 2014;58(06):3570-3571

73 Ferro BE, Srivastava S, Deshpande D, et al. Amikacin pharmacokinetics/pharmacodynamics in a novel hollow-fiber Mycobacterium abscessus disease model. Antimicrob Agents Chemother 2015;60(03):1242-1248

74 Lyu J, Jang HJ, Song JW, et al. Outcomes in patients with Mycobacterium abscessus pulmonary disease treated with long-term injectable drugs. Respir Med 2011;105(05):781-787

75 Ellender CM, Law DB, Thomson RM, Eather GW. Safety of IV amikacin in the treatment of pulmonary non-tuberculous mycobacterial disease. Respirology 2016;21(02):357-362

76 Lee H, Sohn YM, Ko JY, et al. Once-daily dosing of amikacin for treatment of Mycobacterium abscessus lung disease. Int J Tuberc Lung Dis 2017;21(07):818-824
77 Peloquin CA, Berning SE, Nitta AT, et al. Aminoglycoside toxicity: daily versus thrice-weekly dosing for treatment of mycobacterial diseases. Clin Infect Dis 2004;38(11):1538-1544

78 Lee SY, Kim HY, Kim BJ, et al. Effect of amikacin on cell wall glycopeptidolipid synthesis in Mycobacterium abscessus. J Microbiol 2017;55(08):640-647

79 Tsai SH, Lai HC, Hu ST. Subinhibitory doses of aminoglycoside antibiotics induce changes in the phenotype of Mycobacterium abscessus. Antimicrob Agents Chemother 2015;59(10): 6161-6169

80 Pryjma M, Burian J, Kuchinski K, Thompson CJ. Antagonism between front-line antibiotics clarithromycin and amikacin in the treatment of Mycobacterium abscessus infections is mediated by the whiB7 gene. Antimicrob Agents Chemother 2017;61(11):61

81 Olivier KN, Shaw PA, Glaser TS, et al. Inhaled amikacin for treatment of refractory pulmonary nontuberculous mycobacterial disease. Ann Am Thorac Soc 2014;11(01):30-35

82 Rose SJ, Neville ME, Gupta R, Bermudez LE. Delivery of aerosolized liposomal amikacin as a novel approach for the treatment of nontuberculous mycobacteria in an experimental model of pulmonary infection. PLoS One 2014;9(09):e108703

83 Olivier KN, Griffith DE, Eagle G, et al. Randomized trial of liposomal amikacin for inhalation in nontuberculous mycobacterial lung disease. Am J Respir Crit Care Med 2017;195(06): 814-823

84 Mougari F, Bouziane F, Crockett F, et al. Selection of resistance to clarithromycin in Mycobacterium abscessus subspecies. Antimicrob Agents Chemother 2016;61(01):61

85 Choi GE, Shin SJ, Won CJ, et al. Macrolide treatment for Mycobacterium abscessus and Mycobacterium massiliense infection and inducible resistance. Am J Respir Crit Care Med 2012;186 (09):917-925

86 Stout JE, Floto RA. Treatment of Mycobacterium abscessus: all macrolides are equal, but perhaps some are more equal than others. Am J Respir Crit Care Med 2012;186(09): $822-823$

87 Zhang Z, Lu J, Liu M, Wang Y, Zhao Y, Pang Y. In vitro activity of clarithromycin in combination with other antimicrobial agents against Mycobacterium abscessus and Mycobacterium massiliense. Int J Antimicrob Agents 2017;49(03):383-386

88 Ikeda AK, Prince AA, Chen JX, Lieu JEC, Shin JJ. Macrolideassociated sensorineural hearing loss: a systematic review. Laryngoscope 2018;128(01):228-236

89 Albert RK, Connett J, Bailey WC, et al; COPD Clinical Research Network. Azithromycin for prevention of exacerbations of COPD. N Engl J Med 2011;365(08):689-698

90 Haworth CS, Bilton D, Elborn JS. Long-term macrolide maintenance therapy in non-CF bronchiectasis: evidence and questions. Respir Med 2014;108(10):1397-1408

91 Tang S, Yao L, Hao X, et al. Clofazimine for the treatment of multidrug-resistant tuberculosis: prospective, multicenter, randomized controlled study in China. Clin Infect Dis 2015;60(09): 1361-1367

92 Kuaban C, Noeske J, Rieder HL, Aït-Khaled N, Abena Foe JL, Trébucq A. High effectiveness of a 12-month regimen for MDRTB patients in Cameroon. Int J Tuberc Lung Dis 2015;19(05): 517-524

93 van Ingen J, Totten SE, Helstrom NK, Heifets LB, Boeree MJ, Daley $\mathrm{CL}$. In vitro synergy between clofazimine and amikacin in treatment of nontuberculous mycobacterial disease. Antimicrob Agents Chemother 2012;56(12):6324-6327

94 Shen GH, Wu BD, Hu ST, Lin CF, Wu KM, Chen JH. High efficacy of clofazimine and its synergistic effect with amikacin against rapidly growing mycobacteria. Int J Antimicrob Agents 2010; 35(04):400-404

95 Ferro BE, Meletiadis J, Wattenberg M, et al. Clofazimine prevents the regrowth of Mycobacterium abscessus and Mycobacterium 
avium type strains exposed to amikacin and clarithromycin. Antimicrob Agents Chemother 2015;60(02):1097-1105

96 Clofazimine. Tuberculosis (Edinb) 2008;88(02):96-99

97 Nix DE, Adam RD, Auclair B, Krueger TS, Godo PG, Peloquin CA. Pharmacokinetics and relative bioavailability of clofazimine in relation to food, orange juice and antacid. Tuberculosis (Edinb) 2004;84(06):365-373

98 Wallace RJ Jr, Bedsole G, Sumter G, et al. Activities of ciprofloxacin and ofloxacin against rapidly growing mycobacteria with demonstration of acquired resistance following single-drug therapy. Antimicrob Agents Chemother 1990;34(01):65-70

99 Choi GE, Min KN, Won CJ, Jeon K, Shin SJ, Koh WJ. Activities of moxifloxacin in combination with macrolides against clinical isolates of Mycobacterium abscessus and Mycobacterium massiliense. Antimicrob Agents Chemother 2012;56(07):3549-3555

100 Ferro BE, Srivastava S, Deshpande D, et al. Moxifloxacin's limited efficacy in the hollow-fiber model of Mycobacterium abscessus disease. Antimicrob Agents Chemother 2016;60(06):3779-3785

101 Kim J, Sung H, Park JS, Choi SH, Shim TS, Kim MN. Subspecies distribution and macrolide and fluoroquinolone resistance genetics of Mycobacterium abscessus in Korea. Int J Tuberc Lung Dis 2016;20(01):109-114

102 Jeon K, Kwon OJ, Lee NY, et al. Antibiotic treatment of Mycobacterium abscessus lung disease: a retrospective analysis of 65 patients. Am J Respir Crit Care Med 2009;180(09):896-902

103 Wallace RJ Jr, Brown-Elliott BA, Crist CJ, Mann L, Wilson RW. Comparison of the in vitro activity of the glycylcycline tigecycline (formerly GAR-936) with those of tetracycline, minocycline, and doxycycline against isolates of nontuberculous mycobacteria. Antimicrob Agents Chemother 2002;46(10):3164-3167

104 Ferro BE, Srivastava S, Deshpande D, et al. Tigecycline is highly efficacious against Mycobacterium abscessus pulmonary disease. Antimicrob Agents Chemother 2016;60(05):2895-2900

105 Huang CW, Chen JH, Hu ST, et al. Synergistic activities of tigecycline with clarithromycin or amikacin against rapidly growing mycobacteria in Taiwan. Int J Antimicrob Agents 2013;41(03):218-223

106 Wallace RJ Jr, Dukart G, Brown-Elliott BA, Griffith DE, Scerpella EG, Marshall B. Clinical experience in 52 patients with tigecyclinecontaining regimens for salvage treatment of Mycobacterium abscessus and Mycobacterium chelonae infections. J Antimicrob Chemother 2014;69(07):1945-1953

107 Diekema DJ, Jones RN. Oxazolidinone antibiotics. Lancet 2001; 358(9297):1975-1982

108 Dooley KE, Obuku EA, Durakovic N, Belitsky V, Mitnick C, Nuermberger EL; Efficacy Subgroup, RESIST-TB. World Health Organization group 5 drugs for the treatment of drug-resistant tuberculosis: unclear efficacy or untapped potential? J Infect Dis 2013;207(09):1352-1358

109 Srivastava S, Magombedze G, Koeuth T, et al. Linezolid dose that maximizes sterilizing effect while minimizing toxicity and resistance emergence for tuberculosis. Antimicrob Agents Chemother 2017;61(08):61

110 Compain F, Soroka D, Heym B, et al. In vitro activity of tedizolid against the Mycobacterium abscessus complex. Diagn Microbiol Infect Dis 2018;90(03):186-189

111 Zhang Z, Lu J, Song Y, Pang Y. In vitro activity between linezolid and other antimicrobial agents against Mycobacterium abscessus complex. Diagn Microbiol Infect Dis 2018;90(01):31-34

112 Winthrop KL, Ku JH, Marras TK, et al. The tolerability of linezolid in the treatment of nontuberculous mycobacterial disease. Eur Respir J 2015;45(04):1177-1179

113 van Heeswijk RP, Dannemann B, Hoetelmans RM. Bedaquiline: a review of human pharmacokinetics and drug-drug interactions. J Antimicrob Chemother 2014;69(09):2310-2318

114 Andries K, Verhasselt P, Guillemont J, et al. A diarylquinoline drug active on the ATP synthase of Mycobacterium tuberculosis. Science 2005;307(5707):223-227
115 Pang Y, Zheng H, Tan Y, Song Y, Zhao Y. In vitro activity of bedaquiline against nontuberculous mycobacteria in China. Antimicrob Agents Chemother 2017;61(05):pii

116 Huitric E, Verhasselt P, Andries K, Hoffner SE. In vitro antimycobacterial spectrum of a diarylquinoline ATP synthase inhibitor. Antimicrob Agents Chemother 2007;51(11):4202-4204

117 Kakkar AK, Dahiya N. Bedaquiline for the treatment of resistant tuberculosis: promises and pitfalls. Tuberculosis (Edinb) 2014; 94(04):357-362

118 Philley JV, Wallace RJ Jr, Benwill JL, et al. Preliminary results of bedaquiline as salvage therapy for patients with nontuberculous mycobacterial lung disease. Chest 2015;148(02):499-506

119 Olivier KN, Weber DJ, Lee JH, et al; Nontuberculous Mycobacteria in Cystic Fibrosis Study Group. Nontuberculous mycobacteria. II: nested-cohort study of impact on cystic fibrosis lung disease. Am J Respir Crit Care Med 2003;167(06):835-840

120 Levy I, Grisaru-Soen G, Lerner-Geva L, et al. Multicenter crosssectional study of nontuberculous mycobacterial infections among cystic fibrosis patients, Israel. Emerg Infect Dis 2008;14 (03):378-384

121 Martiniano SL, Sontag MK, Daley CL, Nick JA, Sagel SD. Clinical significance of a first positive nontuberculous mycobacteria culture in cystic fibrosis. Ann Am Thorac Soc 2014;11(01):36-44

122 Esther CR Jr, Esserman DA, Gilligan P, Kerr A, Noone PG. Chronic Mycobacterium abscessus infection and lung function decline in cystic fibrosis. J Cyst Fibros 2010;9(02):117-123

123 Waters V, Ratjen F. Antibiotic treatment for nontuberculous mycobacteria lung infection in people with cystic fibrosis. Cochrane Database Syst Rev 2016;12:CD010004

124 Bryant JM, Grogono DM, Greaves D, et al. Whole-genome sequencing to identify transmission of Mycobacterium abscessus between patients with cystic fibrosis: a retrospective cohort study. Lancet 2013;381(9877):1551-1560

125 Binder AM, Adjemian J, Olivier KN, Prevots DR. Epidemiology of nontuberculous mycobacterial infections and associated chronic macrolide use among persons with cystic fibrosis. Am J Respir Crit Care Med 2013;188(07):807-812

126 Coolen N, Morand P, Martin C, et al. Reduced risk of nontuberculous mycobacteria in cystic fibrosis adults receiving long-term azithromycin. J Cyst Fibros 2015;14(05):594-599

127 Broda A, Jebbari H, Beaton K, Mitchell S, Drobniewski F. Comparative drug resistance of Mycobacterium abscessus and $M$. chelonae isolates from patients with and without cystic fibrosis in the United Kingdom. J Clin Microbiol 2013;51(01):217-223

128 Roux AL, Catherinot E, Soismier N, et al; OMA group. Comparing Mycobacterium massiliense and Mycobacterium abscessus lung infections in cystic fibrosis patients. J Cyst Fibros 2015;14(01):63-69

129 Lobo LJ, Chang LC, Esther CR Jr, Gilligan PH, Tulu Z, Noone PG. Lung transplant outcomes in cystic fibrosis patients with preoperative Mycobacterium abscessus respiratory infections. Clin Transplant 2013;27(04):523-529

130 Corris PA. Lung transplantation for cystic fibrosis and bronchiectasis. Semin Respir Crit Care Med 2013;34(03):297-304

131 Osmani M, Sotello D, Alvarez S, Odell JA, Thomas M. Mycobacterium abscessus infections in lung transplant recipients: 15year experience from a single institution. Transpl Infect Dis 2018

132 Gilljam M, Scherstén H, Silverborn M, Jönsson B, Ericsson Hollsing A. Lung transplantation in patients with cystic fibrosis and Mycobacterium abscessus infection. J Cyst Fibros 2010;9(04): 272-276

133 Qvist T, Pressler T, Thomsen VO, Skov M, Iversen M, Katzenstein TL. Nontuberculous mycobacterial disease is not a contraindication to lung transplantation in patients with cystic fibrosis: a retrospective analysis in a Danish patient population. Transplant Proc 2013;45(01):342-345

134 Robinson PD, Harris KA, Aurora P, Hartley JC, Tsang V, Spencer H. Paediatric lung transplant outcomes vary with Mycobacterium abscessus complex species. Eur Respir J 2013;41(05):1230-1232 
135 Longworth SA, Vinnard C, Lee I, Sims KD, Barton TD, Blumberg EA. Risk factors for nontuberculous mycobacterial infections in solid organ transplant recipients: a case-control study. Transpl Infect Dis 2014;16(01):76-83

136 Longworth SA, Blumberg EA, Barton TD, Vinnard C. Non-tuberculous mycobacterial infections after solid organ transplantation: a survival analysis. Clin Microbiol Infect 2015;21(01):43-47

137 Morales P, Gil A, Santos M. Mycobacterium abscessus infection in transplant recipients. Transplant Proc 2010;42(08):3058-3060

138 Knoll BM, Kappagoda S, Gill RR, et al. Non-tuberculous mycobacterial infection among lung transplant recipients: a 15-year cohort study. Transpl Infect Dis 2012;14(05):452-460

139 Chernenko SM, Humar A, Hutcheon M, et al. Mycobacterium abscessus infections in lung transplant recipients: the international experience. J Heart Lung Transplant 2006;25(12):1447-1455

140 Choi H, Kim SY, Kim DH, et al. Clinical characteristics and treatment outcomes of patients with acquired macrolide-resistant Mycobacterium abscessus lung disease. Antimicrob Agents Chemother 2017;61(10):61

141 Lyu J, Kim BJ, Kim BJ, et al. A shorter treatment duration may be sufficient for patients with Mycobacterium massiliense lung disease than with Mycobacterium abscessus lung disease. Respir Med 2014;108(11):1706-1712

142 Koh WJ, Jeong BH, Jeon K, et al. Oral macrolide therapy following short-term combination antibiotic treatment of Mycobacterium massiliense lung disease. Chest 2016;150 (06):1211-1221

143 Zelazny AM, Root JM, Shea YR, et al. Cohort study of molecular identification and typing of Mycobacterium abscessus, Mycobacterium massiliense and Mycobacterium bolletii. J Clin Microbiol 2009;47:1985-1995

144 Harada T, Akiyama Y, Kurashima A, et al. Clinical and microbiological differences between Mycobacterium abscessus and Mycobacterium massiliense lung diseases. J Clin Microbiol 2012; 50:3556-3561

145 Kim HY, Kook Y, Yun YJ, et al. Proportions of Mycobacterium massiliense and Mycobacterium bolletii strains among Korean Mycobacterium chelonae-Mycobacterium abscessus group isolates. J Clin Microbiol 2008;46:3384-3390

146 Lee SH, Yoo HK, Kim SH, et al. The drug resistance profile of Mycobacterium abscessus group strains from Korea. Ann Lab Med 2014;34:31-37 